University of Louisville

ThinkIR: The University of Louisville's Institutional Repository

Electronic Theses and Dissertations

$12-2008$

\title{
Op art : perceptions of reality.
}

Christine Michelle Humphrey 1982-

University of Louisville

Follow this and additional works at: https://ir.library.louisville.edu/etd

\section{Recommended Citation}

Humphrey, Christine Michelle 1982-, "Op art : perceptions of reality." (2008). Electronic Theses and Dissertations. Paper 653.

https://doi.org/10.18297/etd/653

This Master's Thesis is brought to you for free and open access by ThinkIR: The University of Louisville's Institutional Repository. It has been accepted for inclusion in Electronic Theses and Dissertations by an authorized administrator of ThinkIR: The University of Louisville's Institutional Repository. This title appears here courtesy of the author, who has retained all other copyrights. For more information, please contact thinkir@louisville.edu. 


\title{
OP ART: PERCEPTIONS OF REALITY
}

\author{
By \\ Christine Michelle Humphrey \\ M.A., Schneider Hall, 2008
}

\begin{abstract}
A Thesis
Submitted to the Faculty of the

Graduate School of the University of Louisville

in Partial Fulfillment of the Requirements

for the Degree of
\end{abstract}

Master of Arts

Department of Fine Arts

University of Louisville

Louisville, Kentucky

December, 2008 


\title{
OP ART: PERCEPTIONS OF REALITY
}

\author{
By
}

Christine Michelle Humphrey

M.A., Schneider Hall, 2008

A Thesis Approved on

December 2, 2008

by the following Thesis Committee:

John Begley, Thesis Director

Susan Jarosi

Tom Maloney 


\section{DEDICATION}

This thesis is dedicated to my parents

Mr. Jimmy Edward Humphrey

and

Mrs. Carolyn Humphrey

who have always provided encouragement and support of my educational pursuits. 


\section{ACKNOWLEDGMENTS}

I would like to thank my professor and mentor, John Begley, for the knowledge I have acquired while being his student as well as for the learning opportunities and advice he has provided. I would also like to thank Susan Jarosi for her assistance as a committee member as well as for all she has taught me as my professor over the past two years. I would also like to thank Professor Tom Maloney for serving as my committee member. Also, thank you to my family for always supporting and encouraging me. 


\section{ABSTRACT \\ OP ART: PERCEPTIONS OF REALITY}

Christine M. Humphrey

December 5, 2008

This thesis and exhibition examine the connection between neurobiology and Op Art. Neurobiological explanations of Op Art's effects are explored as a means to offer insight into the processes of the human mind and eye, and to provide explanations for the optical phenomena that were of interest to the Op artists. The initial chapter provides an overview of Op Art that is intended to offer the viewer a context for understanding the works. It also includes an explanation of the works included in the exhibition. The exhibition showcases examples of Op Art from the University of Louisville's collections as well as work borrowed from local collectors and artists. Visual impairments are also discussed as a means to provide the reader with further information on individual perception, which was the primary focus of Op artists. The thesis concludes with a summary of why an investigation into the neurobiological activity and an individual perception is significant for Op Art. The neurobiology of our brain determines our perceptions which vary from person to person. Illusions in Op Art, when perceived by an individual, provide powerful bodily sensations that lead to the inquiry of how we perceive the world around us. These reactions are what the Op artists explored in their work as a means to raise the viewer's consciousness about perception and reality. 
TABLE OF CONTENTS

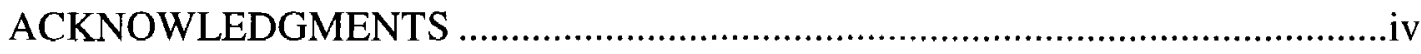

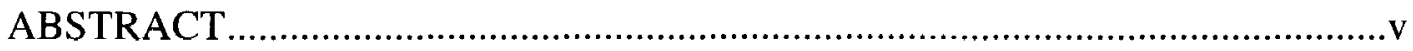

CHAPTER

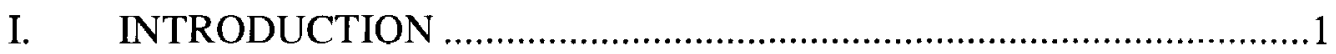

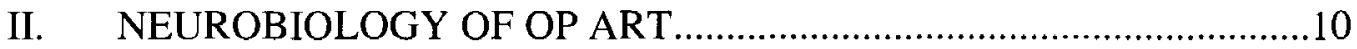

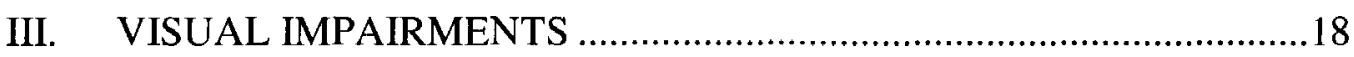

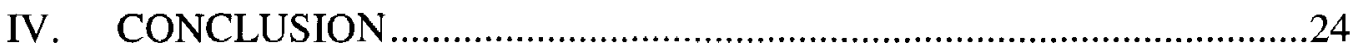

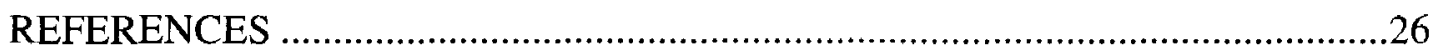

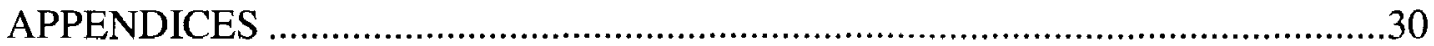

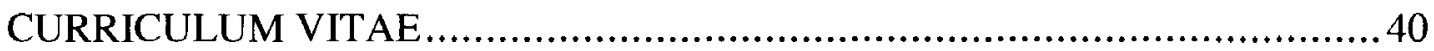

ADDENDUM 


\section{CHAPTER I \\ INTRODUCTION}

Since Op Art first appeared in the mid 1960's, it has been said to cause nausea, even to the extent of causing some viewers to faint. The reasons that help explain these physical reactions are explored in this thesis and offer broader insight into the importance of our individual perception (our way of seeing) and a greater understanding of how we create the reality we live in. Op Art shows that what we see is more complicated than what meets the eye, because it is the circumstances that meet the eye that determine how it is perceived, and therefore not everyone sees the same thing. Circumstances include factors such as light or the surrounding environment.

The Museum of Modern Art's 1965 exhibition The Responsive Eye marked the beginning of the cultural Op Art phenomena in America. Curated by William Seitz, The Responsive Eye "was in a sense the first contemporary art blockbuster."1 Seitz curated the exhibition by including abstract works that utilized the effects of black and white, color juxtaposition, illusory movement, moiré patterns and kinetic sculpture which my thesis exhibition also incorporates. David Rimanelli, author of the article "Beautiful Loser: Op Art Revisited" explores the resurgence of Op Art since its popular arrival in the 1960's. He reviews two major exhibitions within the past two years which point to the continued

\footnotetext{
' David Rimanelli, "Beautiful Loser: Op Art Revisited," Artforum 45, no. 9 (2007): 315.
} 
interest in Op Art: Optic Nerve: Perceptual Art of the 1960s at the Columbus Museum of Art in Ohio, and $O p A r t$ at the Schirn Kunsthalle in Frankfurt. Of these two exhibitions, Rimanelli asserts, "they restore Op as a subject of genuine fascination.", The catalogue to Optic Nerve describes the significance of Op Art saying, "The Op Art movement pioneered the integration of technology into art, innovated the concept of viewer participation, and introduced an emphasis on immersive experience, ideas that contemporary art now embraces and incorporates." "Op Art stresses the individual sensory experiences and psychological responses of each viewer, enabling everyone to have a unique reaction to the works featured." "This individuality of experience is emphasized in my thesis and exhibition. In the Schirn Op Art catalogue the goal of Op Art is described by claiming, "Op Art made not only the analysis of seeing it's task, but integrated in its conception almost the entire sensory apparatus which is manifested specifically in its participatory aspects in that besides analyzing perception viewers and their movement in front of the object became central." When explaining what Op Art is Weinhart says, "an art of perception that is based on the deliberate confusion of vision, indicating that the most important feature of Optical Art lies in its effect on certain physiological processes of the eye and brain of which we are not normally conscious, neither in everyday seeing nor in observing everyday artworks." ${ }^{, 6}$ My thesis and exhibition have built on these previous exhibitions and added the emphasis on

\footnotetext{
${ }^{2}$ Ibid., 316 .

${ }^{3}$ Joe Houston, Optic Nerve: Perceptual Art of 1960's (London New York: Merrell, 2007), 7.

${ }^{4}$ Ibid.

${ }^{5}$ Martina Weinhart, Mark Hollein, and Frances Follin, Op Art, ( Frankfurt: Schirn Kunsthalle, 2007), 10

${ }^{6}$ Ibid., 28.
} 
neurobiology which allows the viewer to understand more about how we see and what dictates an individual perception.

The recent resurgence of $\mathrm{Op}$ and the exploration into the reasons for its revival led to the inspiration for the exhibition curated to accompany this thesis, entitled $O p A r t$ : Perceptions of Reality. The reason for my curatorial interest in Op Art derives from a desire to present to the public an art form that fascinates with its instant visceral impact and leaves viewer's with a heightened awareness of their reality. Op Art physically impacts the viewer, delivering a shock to the body which causes the viewer to question the way our mind processes images and to further investigate how we construct the world we live in through our perception. The physical impact is caused by the visual disorientation that occurs when viewing Op Art and varies from person to person. This exhibition and thesis seek to thoroughly explore and explain how Op Art strikes such a responsive chord within the human perceptual realm.

Op Art: Perceptions of Reality reexamines Op Art from the framework of neurobiological explanation behind the illusory phenomena that are specific to Op Art. Most of the artists chosen for the exhibition Op Art: Perceptions of Reality have work in the University of Louisville's permanent collection. They were chosen for the commonality their works share in illustrating that our construction of reality involves complex neurobiological factors that shape our perception. By observing the illusory phenomena Op Art produces, the viewer can be led to question the reasons into why and how our eyes, mind, and body react the way they do. The artists included in Op Art: Perceptions of Reality are Yaakov Agam, Joseph Albers, Richard Anuszkiewicz, Benjamin Cunningham, Sally Drummond, Bridget Riley, Julian Stanczak, Victor 
Vasarely, and John Whitesell. Many of these artists have exhibited work together, were students under Josef Albers or influenced by his teachings and were working during the height of the Op Art movement. Together they present a consistently intriguing exploration of our view of the world and how we perceive it.

Cyril Barrett says, the term "Op" short for optical, was first used in the Time magazine article "Op Art Pictures that Attack the Eye," from 1964. ${ }^{7}$ Barrett examines what distinguishes Op from other art in his book $O p$ Art, and claims that, "this art made use of certain optical effects." ${ }^{, 8}$ This explanation may seem as though it can be applied to any art but as Barrett makes clear, Op Art came from the "evolution of abstraction." Historically, the development Op Art can be traced back as far as the Impressionists and their concern with light and color. But as Barrett clarifies, the Impressionists were using figures in their work and mostly experimenting with light and its reflection from objects. ${ }^{10}$ Barrett then explores how the work of Seurat and the Neo- Impressionists were influential to Op. " Seurat made use of the optical theory of his time and applied it to his experiments with color mixing. ${ }^{12}$ The Post-Impressionists, such as Kandinsky, and their "exploration of pure color" were additional precursors which led to the Op Art movement. ${ }^{13}$ Op Art's abstract forms were influenced by the geometric abstraction of Constructivism and Suprematism. Barrett includes a quote by the Op artist Jesus-Raphael Soto and his reactions to the Suprematist work of Malevich which states, "it is the sign of

\footnotetext{
${ }^{7}$ Cyril Barrett, Op Art (New York: A Studio Book The Viking Press, 1970), 5.

${ }^{8}$ Ibid.

${ }^{9}$ Ibid., 7.

${ }^{10}$ Ibid.

${ }^{11}$ Ibid., 8.

${ }^{12}$ Ibid.

${ }^{13}$ Ibid., 9.
} 
reality which he gives us; not the naturalist rendering of it." ${ }^{14}$ The late work of Mondrian was inspiring to Op artists because of its optical effect, or flickering, as can be seen in Broadway Boogie Woogie (1942-3). ${ }^{15}$ Barrett also mentions the Futurist Giacomo Balla and his Electric Lamp (1909) as having a strong optical flicker effect. ${ }^{16}$ According to Barrett, Balla created some of the very first Op Art works. ${ }^{17}$ Barrett includes Marcel Duchamp's Fluttering Hearts (1936) as another one of the first Op Art works. ${ }^{18}$ Barrett notes that this work employs optical phenomena such as "flicker, after-image and advance and recession of colors" that became important components for Op artists. ${ }^{19}$ Barrett goes on to say that the Bauhaus teacher Joseph Albers' experiments with color were also of great influence to Op artists such as Richard Anuszkiewicz and Julian Stanczak, who were students of his at Yale University in the early 60 's. ${ }^{20}$ In Interaction of Color Joseph Albers writes, "In visual perception color is almost never seen as it really is as it physically is."21 One of Albers' examples shows that everyone has unique color perception and that no one color has a definite hue. He suggests thinking of the color red, and notes that the color red that each individual thinks of will vary. ${ }^{22}$ Albers created work that responded according to the context in which it was represented, thus demonstrating the many possibilities of perception. By juxtaposing colors they can be modulated in apparent value and hue by changing their own position. Albers said, "When you really

\footnotetext{
${ }^{14}$ Ibid., 12.

${ }^{15}$ Ibid., 14.

${ }^{16}$ Ibid., 16.

${ }^{17}$ Ibid., 29.

${ }^{18}$ Ibid., 31.

${ }^{19}$ Ibid.

${ }^{20}$ Ibid., 32.

${ }^{21}$ Joseph Albers, Interaction of Color: Revised and Expanded Edition (New Haven and London: Yale University Press, 2006), 1.

${ }^{22}$ Ibid., 3.
} 
understand that each color is changed by a changed environment, you eventually find that you have learned about life as well as about color.,"23

The characteristics of Op Art according to Barrett are: "the repetition of simple elements, calculation, the use of complementary colors, the exclusion of perspective devices and spatial ambiguities, and a direct perceptual appeal without symbolism or association." ${ }^{24}$ Op works are "an attempt to produce pictures which give an impression of movement without actually moving." 25 The direct perceptual appeal is investigated throughout this thesis by emphasizing the individual viewpoint which is significant to Op Art and which allows the viewer to gain an understanding of how we shape our world according to our own perception.

The Op artists were interested in illusions that create optical effects. Many Op artists employed the use of black and white, including Bridget Riley and Victor Vasarely. Barrett explains that many optical effects can be achieved by using black and white alone. ${ }^{26}$ Riley's Fall, included in Op Art: Perceptions of Reality, is an example of what Barrett refers to in his book as a "periodic structure" which is a repetition of geometric patterns. ${ }^{27}$ The optical effect produced by the repetition of patterns is explored further in the upcoming chapter on neurobiology. Another illusory phenomenon is afterimages or after- effects, which are common when viewing Op Art. These are spots of light that seem to float in front of the eye and are categorized as positive and negative. The positive after-image, or bright light, is caused by the "continuing firing of the retina and the optic

\footnotetext{
${ }^{23}$ Fronia Wissman, Albers (New Haven, Connecticut: University Art Gallery, 1978), 14.

${ }^{24}$ Barrett, "Op Art," 35.

${ }^{25}$ Ibid., 37.

${ }^{26}$ Ibid., 38.

${ }^{27}$ Ibid.
} 
nerve after the stimulation. ${ }^{28}$ The negative after-image, or dark light, is caused by "reduced sensitivity of the stimulated part of the retina due to the bleaching of the photopigment." ${ }^{29}$ John Whitesell's Resonance I included in this thesis exhibition and Riley's Fall both demonstrate this effect. The moiré effect was also of interest to the Op artists. This effect requires the overlapping of line patterns. ${ }^{30}$ Victor Vasarely's transparencies exhibited in this thesis show from the books Vasarely: Plastic Arts of the 20th Century and Vasarely II: Plastic Arts of the 20th Century both display examples of the moiré effect. The moiré effect works by moving the top transparency over the bottom sheet, or by physically moving in front of the two static sheets. Whitesell's Red Print, Lorelei, and Homage to Malevich also use the moiré patterns to achieve their dynamic effect.

The Op artists were also interested in color effects and exploited these possibilities in new ways. Vasarely's print Untitled (geometric composition), included in the exhibition is an example of simultaneous contrast. ${ }^{31}$ Simultaneous contrast occurs when two colors juxtaposed modify the complimentary of its own color. Vasarely's blue circle is placed in proximity to both white and black, allowing the blue to change to a lighter blue if viewed next to the white region and darker if viewed next to the black. ${ }^{32}$ The blue looks brighter when compared to black, because white is the complementary of black, thus the blue is modified in the direction of white. Vasarely's experiments with the juxtaposition of colors can also be seen in his Untitled (blues, gold, violet on brown) also included in the exhibition.

\footnotetext{
${ }^{28}$ Ibid., 55 .

${ }^{29}$ Ibid.

${ }^{30}$ Ibid., 66.

${ }^{31}$ Ibid., 72.

${ }^{32}$ Ibid.
} 
Op Art demonstrates both how human visual perception operates and how our perceptual faculties construct the reality in which we live. As humans we have adapted our perceptions of the world around us to maintain a physical and mental balance within everyday life. By examining how our perception can distort this reality through the form of illusions, we can subsequently learn more about our mind and our world by examining how our perception can distort this reality in the form of illusions. A broader understanding of reality can be understood by observing the illusory phenomenon of Op Art. This goal of understanding reality and its multiple possibilities was part of the inspiration for Op Art. In Yaacov Agam's Untitled kinetic piece as it shifts and creates constantly changing patterns that changes the viewer's perceptions of it; it presents multiple visual options and points to a universe of contiguous but multiple or alternative dimensions. Agam is inspired by the idea of a space-time continuum and the fourth dimension and offers multiple viewpoints in his work as a visual representation of this idea. His kinetic art is directly related to his ideas about a continuous universe, one that is not static but always moving.

Op Art's abstraction combined with its physically exciting illusory effects provides a deeper contemplation about human perception. Op Art provides the viewer with an instant sensation whose unsettling effects provoke greater questions into how we perceive the world. Both Benjamin Cunningham and Sally Drummond's paintings included in the exhibition have a sense of depth that lure the viewer inside the canvas. Cunningham's' circles and squares offer illusions of depth and seem to float like wormholes to another dimension. Drummond's tiny dots pulsate and together resemble 
galaxies in outer space offering the instant sensation that light is being emitted from within the canvas itself implying other worlds.

The science of neurobiology was undergoing a period of great growth in its understanding of how human perception occurs at the same time that Op Art became a popular, mass cultural art form. These new scientific ideas influenced many Op artists, particularly in their understandings of perception and the explanation of the illusory phenomena of Op Art. Op Art connected art and neurobiology and indeed each field were influenced by the other. Neurobiologists saw in Op Art about the visual processes that they were discovering that operate in our mind and eye, and artists gained understanding of why these phenomena worked. 


\section{CHAPTER II \\ NEUROBIOLOGY OF OP ART}

It is the neurobiology of our brain that determines the process of how our mind shapes our perceptions. To fully understand how we see we must first understand light. Thanks to the experiments of Isaac Newton, we know that white light can be divided into colors, and colored light can also be combined to create white light. The electromagnetic radiation, or light, that we see are between waves between 370-730 nanometers in length, and we have receptors in our eyes that respond to just these types of wavelengths. ${ }^{33}$ The colors that we see are different depending on the wavelength of light. Light passes through the pupil at the front of our eye, while the lens focuses the image onto the retina, a sheet of neural tissues at the back of the eyeball. ${ }^{34}$

The neural tissue is made up of ganglion, bipolar, and horizontal cells, while the back layer contains the photoreceptors. ${ }^{35}$ The photoreceptors are the cells that respond to light, they absorb light, and then send a signal back through the horizontal, bipolar, and ganglion cells which then send their signals through the optic nerve in the eye to the brain. ${ }^{36}$ Our photoreceptors are made up of cells called rods and cones: cones are used for

\footnotetext{
${ }^{33}$ Margaret Livingston, Vision and Art: The Biology of Seeing (New York, NY: Harry N. Abrams Incorporated, 2002), 17.

${ }^{34}$ Ibid., 24.

${ }^{35}$ Ibid.

${ }^{36}$ Ibid.
} 
daylight while rods are used for the darker conditions. ${ }^{37}$ We have three different types of cones which are sensitive to long, middle, and short wavelengths. ${ }^{38}$ We all have only one type of rod which is why we cannot see color in darkness, since there must be more than one type of photoreceptor for the activity to be compared to in order to distinguish colors. ${ }^{39}$

We know that an object's color is dependent on the wavelengths of light it reflects. The colors we see everyday are also dependent on the given levels of light in which we view them, their luminance. In art this is referred to as value, or the contrasting light and shade in a picture. Our color perception can change depending on the luminance and how it affects our rods and cones. In Vision and Art the Biology of Seeing Margaret Livingston believes luminance is the most important quality in visual perception for the way it "defines shape, texture, and line." 40 Throughout her research Livingston provides examples of the very different roles color and luminance play in art. ${ }^{41}$ The science of color and luminance were what Joseph Albers, who influenced Op Artists, explored in his teachings about color and its environment. Livingston explains that our ganglion cells are organized by what is called a center/surround structure. The ganglion cells in our retina are made active (signaled) by the small spots of light that fall on their center region and suppressed by the light that falls on the surrounding region. ${ }^{42}$ This organization makes our cells sensitive to small spots of light because the small spots activate the cells better than the large spots of light. ${ }^{43}$ The center/surround organization explains the way our eye

\footnotetext{
${ }^{37}$ Ibid., 26.

${ }^{38}$ Ibid., 27.

${ }^{39}$ Ibid., 26.

${ }^{40}$ Ibid., 10.

${ }^{41}$ Ibid.

${ }^{42}$ Ibid., 53.

${ }^{43}$ Ibid.
} 
perceives and reacts to many of the visual patterns and phenomena in Op Art. The change of value causes the eye to see dark spots where there are not any. We perceive the spots to be there because the center/surround cells which depict light are more suppressed in the surround area than in the center. The surround cells are suppressed and therefore the dark illusory spots appear. Riley's Fall provides an example of this phenomenon.

In the article "Afterimage of Perceptually Filled in Surface," published in the journal Science, an afterimage is "believed to be to be due to bleaching of photochemical pigments or neural adaptation in the retina." 44 The article reports on experiments conducted on both local (negative) and global (positive) afterimages and explains "the rivalry between the local and the global afterimages may be considered as suppression between two cortical representations." ${ }^{, 45}$ Because the center response is more rapid than the surround response, we perceive the darker spots to flicker. ${ }^{46}$ The motion effect in Op Art can be explained by the flickering caused by the center/surround organization of the ganglion cells and the slower response time. Black and white works, such as Riley's Fall provides an example of this motion effect in which the lines seem to move in and out.

This article is another illustration of the many connections between Op Art and neurobiology.

Livingston explains that "neurons respond best to sharp changes, rather than gradual shifts in luminance. ${ }^{, 47}$ She says our biological system is designed this way in an effort to conserve energy and make nerve cells more efficient. ${ }^{48}$ This explains why two

\footnotetext{
${ }^{44}$ Shinsuke Shimojo, “After-Image of a Perceptually Filled In Surface," Science 293, no. 31 (Aug. 2001): 1677.

${ }^{45}$ Ibid., 1680.

${ }^{46}$ Livingston, Vision and Art, 56.

${ }^{47}$ Ibid., 54.

${ }^{48}$ Ibid.
} 
identical shades of gray look different depending on the background. This is also what Albers demonstrates in his experiments with color as the pages from the Interaction of Color included in the exhibition illustrate. In reference to the difference in gray color, Livingston uses a newspaper print and a shadow of a tea canister as an example, and says, "the explanation must be due to the fact that the visual system ignores the gradual change in luminance due to the shadow of the tea canister and instead registers predominantly local differences in luminance-the letters against the type-by virtue of center/surround organization. ${ }^{, 49}$ By changing the background to a color, as Albers does the gradual shifts in luminance, ignored by the ganglion cells, allow the same color to look darker or lighter, depending on the background surrounding it.

In an effort to explain the organization of eye, Livingston refers to a "Where" and "What" system which she uses to differentiate between respective roles. She explains that motion perception, depth perception, figure/ground segregation and information about positions are colorblind and only respond to luminance. ${ }^{50}$ These aspects of visual perception which Livingston refers to as the "Where" system, are found in all mammals and are evolutionary older than the visual perception aspects used for color. ${ }^{51}$ Object and face recognition are referred to by Livingston as the "What" system and rely on color for perception. ${ }^{52}$ The "Where" system is highly sensitive to contrast, which means that for depth perception to be perceived a high contrast in luminance must be available. Because the "Where" system detects depth and motion, Op artists accentuated the luminance of color, or value, since our eyes are sensitive to the changes in the value of color depending

\footnotetext{
${ }^{49}$ Ibid., 58.

${ }^{50}$ Ibid.

${ }^{51}$ Ibid., 50.

${ }^{52}$ Ibid.
} 
on its luminance and to achieve their intended effect of making the viewer self aware of the process of perception. Livingston provides examples of paintings shown in grayscale, such as Monet's Impression Sunrise to demonstrate this phenomenon. ${ }^{53}$ Reproducing this work in grayscale shows the sun equiluminant with the sky, but viewed in its original color, the sun is painted an unnatural brightness against the sky. The Impressionists and artists such as Mondrian created movement in their work by incorporating equiluminant colors that provided their paintings with the look of movement that was subsequently influential for the future $O p$ artists.

Livingston describes the original sun in Monet's painting as "eerie," because of this equiluminosity. Because our "Where" system depicts motion and positions through luminance, and the sky and sun are equiluminant, we view the scene as motionless and without a position. ${ }^{54}$ When two colors are equal in value it is difficult to distinguish figure/ground. This results in a jittery image when viewed because the colors are both lighter and darker than each other. ${ }^{55}$

Livingston uses Op artist Richard Anuszkiewicz's Plus Reversed (1960) to further illustrate equiluminosity. She explains, "The 'What' system can see the shapes because of the strong color contrast, but since the 'Where' system can't (because it cannot distinguish equiluminant colors), it can't assign them positions, making the image seem unstable and jittery." ${ }^{, 56}$ Livingston says that it is the equiluminance of colors that causes the work to be "jarring," which can account for the aggressiveness that many feel when viewing Op. Because the "Where" system cannot distinguish between the colors, it sees

\footnotetext{
${ }^{53}$ Ibid., 38.

${ }^{54}$ Ibid., 40.

${ }^{55}$ Ibid., 66.

${ }^{56}$ Ibid.
} 
them as "simultaneously both lighter and darker than the other, which makes the painting appear to pulsate." 57

Both Anuszkiewicz's Illustration for the Inward Eye and Inward Eye shown in this exhibition take advantage of human neurobiology to achieve this effect. Anuszkiewicz was working with what he had learned from Albers' teachings of the interaction of color. Specifically, the interactions, or color energy, created when different colors are juxtaposed. ${ }^{58}$ Stanczak's Filtration as well as Whitesell's Resonance I also produce this effect causing the eye to jump from one point to the next across the canvas. In Filtration, the use of multiple juxtaposed colors and grid structure also point to Stanczak's fascination with space and the multiple views one can have of reality. ${ }^{59}$ In 1965 Stanczak wrote "In my work, I do not try to imitate or interpret nature; but with the response to the behavior of color, shape, lines, I try to create relationships that would run parallel to man's experiences with reality. ${ }^{60}$ Whitesell was influenced by Albers and his theories of color and juxtaposition. He says that although he and other artists working in similar styles at the time did not completely understand the specifics of the processes that the eye and brain underwent, they were able to exploit these visual phenomena within their work. The idea of a unique individual viewpoint and particular experience is also one that he finds intriguing and can be observed in his prints.

Moiré is another optical phenomenon that occurs when two patterns are placed on top of each other. The moire is the new pattern that is formed when the lines of the two intersect. The new pattern creates an effect of motion which is determined by the spacing,

\footnotetext{
${ }^{57}$ Ibid.

${ }^{58}$ Karl Lunde, Richard Anuszkiewicz (New York: Harry N. Abrams Incorporated, 1977), 37

${ }^{59}$ Ibid., 96.

${ }^{60}$ Ibid., 74.
} 
or distance, of the two original patterns. It is the viewer who determines the motion as the eye moves across the surface. The effects of moire depend on the degree of angle and curve pattern and intersection with the viewer's eyes.

Op Art works such as Bridget Riley's Fall incorporates both depth and movement and the depth can be explained by the repetition of patterns. The retinas, responsible for matching images, cannot decipher between repetitive patterns in a two-dimensional scene. The repetition of pattern causes the retina to confuse the matching of images since any part of the scene could be correct. The illusion of depth is created, because usually when looking at a three-dimensional plane, the retinas understand other images as being in front of or behind the focal point. ${ }^{61}$

Another interesting effect of Riley's work, Fall is that the curves in her work are placed in varying widths and are placed at different distances apart with some lines being much closer together than others. This seems to reinforce the depth perception and cause a sense movement. In the journal Spatial Vision J. Zanker uses Riley's Fall to explore how motion perceived when viewing the work. He experimented with measurements of the eye movements that a person has when viewing Riley's Fall. Zanker uses the Op painting to understand "how the human visual system usually compensates for eye movements, to let us perceive a stable world despite continuous image shifts generated by gaze instability." 62 The study of Riley's Fall led to many questions about involuntary eye movements and our visual system. "Op Art can prove to be much more for scientists than just an interesting sensation, however pleasant, provocative or puzzling it may be, because it provides the occasion for understanding fundamental mechanisms of visual

\footnotetext{
${ }^{61}$ Ibid., 146.

${ }^{62}$ J Zanker, “Looking at Art from a Computational Viewpoint," Spatial Vision 17, no. 1-2 (2004): 75.
} 
processing in highly evolved nervous systems. ${ }^{" 63}$ Zanker also says that Op Art such as Riley's "challenges our understanding of the human visual system." ${ }^{\text {"Th }}$ The illusory effects of Op Art cause scientists to further explore the mechanics of vision.

${ }^{63}$ Ibid., 92.

${ }^{64}$ Ibid., 93. 


\section{CHAPTER III}

\section{VISUAL IMPAIRMENTS}

The illusions observed in Op Art can vary in effect from person to person, thus privileging individual perception. This individuality of experience also inspired the Op artists. It is remarkable to learn that many artists throughout history have refused treatment for their visual impairments. It is intriguing that individuals choose to perceive the world in an altered view and have chosen to express it through art. Research has indicated that many visually impaired persons are grateful for the unique way in which they see the world, and blind artists have argued that it adds to their creativity. The following story of Mike May offers a greater understand of how we perceive images.

Robert Kurson's Crashing Through: A True Story of Risk, Adventure, and the Man Who Dared to See describes the incredibly inspiring story of Mike May and his difficult transition from being completely blind to obtaining perfect vision. May was in need of stem cells that could produce daughter cells, which keep the cornea clear and free from infection, after his were destroyed in an explosion.

For May, color and motion were easily identifiable because they are one of the first things an infant learns. Because May lost his sight at the age of three, more complicated visual knowledge, such as facial recognition, spatial depth, and object recognition were impossible to discern. Kurson explains that assumptions imprinted in 
the brain, since infancy, will trump illusions every time. This is because our knowledge and assumptions about the world are critical to how we perceive images. ${ }^{65}$ Human experience is so important to vision, that even if we tell our brain, for instance, that a mask is hollow, we will perceive the face as protruding outward, because that is what we have experienced our entire lives. ${ }^{66}$

Kurson describes an experiment conducted by Richard Held and Alan Hein at MIT in which two kittens were kept in the dark and placed in baskets that were hung from the same pole above the ground. One basket had holes cut into it so that the kitten could explore the world. When the kittens were removed, only the kitten that was allowed to explore the world physically could function. The other kitten was left blind by the experience because it never touched the ground, and only explored the world passively hanging in the basket. ${ }^{67}$ This explains the critical need for experience of the world that is required for functional vision.

Ione Fine conducted tests on May's vision to better understand the brain's role and the importance of knowledge and experience in vision. She explained to May how rare his case was, fewer than twenty people known to history had restored vision after a lifetime of total blindness. The tests showed that May could not distinguish between faces, and was unable to distinguish between male and female or whether an image of a face had upside down features. ${ }^{68}$ Interestingly, when an image was shown in depth, such as a cube, May was unable to identify it, but shown in motion, he knew instantly that it

\footnotetext{
${ }^{65}$ Robert Kurson, Crashing Through: A True Story of Risk, Adventure, and the Man Who Dared to See (New York, NY: Random House, 2007), 232.

${ }^{66} \mathrm{Ibid}$.

${ }^{67}$ Ibid., 283.

${ }^{68}$ Ibid., 220.
} 
was a cube. Optical illusions had no effect on May; he was able to instantly decipher them.

Fine's tests showed that he was unable to practice with the everyday encounter of faces and objects in the world, therefore he never gained the ability to understand expressions, mood, or depth. ${ }^{69}$ Kurson explains that our depth perception comes from cues, the same things that the Renaissance artists utilized in their paintings. Some of these include: occlusion, perspective, texture, shading, relative size, and relative height. Our brain processes all of these cues to help in our understanding of the visual world.

Kurson explains that May understood the cube when it was in motion, because we learn motion within a few weeks of age, and pictorial cues can take much longer to be fully understood. Object perception is just as complicated and takes years to perfect. Object perception was impossible because May only saw in two dimensions. The recognition of faces, depth, and objects is complex because of the numerous factors it relies on, such as cues, clues and context. ${ }^{70}$

Fine hoped that May's vision could be improved, but after numerous hours of brain x-rays, she discovered that he had lost the neurons necessary for the understanding of depth, facial, and object recognition. Kurson explains that the human brain contains approximately 100 billion neurons, and children have an over abundance of neurons. If these neurons are not assigned a job, they will be lost, precisely what May experienced. May's visual neurons had gone off to represent other complex tasks that needed them,

\footnotetext{
${ }^{69}$ Ibid., 241.

${ }^{70}$ Ibid., 253.
} 
including echolocation. The other neurons left without a job simply died and were gone forever, leaving it impossible for May to have functional vision. ${ }^{71}$

May is extraordinary not only for his braveness throughout life, but for the way in which he handled difficult situations with his new sighted life. Unable to accept this type of vision, he taught himself to see, by "seeing" blind. In an amazingly creative and difficult solution to his problem with seeing images, May decided to give priority to the senses he used when he was blind. He decided to continue using his guide dog and cane, echolocation, as well as Braille for reading. He incorporated his memory and organization to build a catalogue of things he saw, and taught himself to see automatically. ${ }^{72}$

The following research is included to provide the reader with an understanding that individual perception was inspiring to the Op Artists and that this is a concept that can be understood by learning about how the visually impaired use their own sense of individual perception. The works included in Op Art: Perceptions of Reality explores the idea of an individual perception such as Albers' experiments in color perception and Agam's kinetic work that offers the viewer multiple viewpoints.

The exhibition entitled Art of the Eye: An Exhibition on Vision, conceived by the artist Scott Nelson, explores aesthetically the way in which the visually impaired see. Nelson was inspired by his own visually impaired experience after being diagnosed with retinitis pigmentosa. He explains that Art of the Eye was a collaborative effort that included research from ophthalmology, optometry, visual psychology and art history. ${ }^{73}$

\footnotetext{
${ }^{71}$ Ibid., 256.

${ }^{72}$ Ibid., 273.

${ }^{73}$ Scott Nelson, Art of the Eye: An Exhibition on Vision (St. Paul, MN: Gamma Foundation and FORECAST, 1986), 10.
} 
The goals of this exhibition were to present visually impaired persons with the opportunity to feature their art on the same level as work of sighted artists as well as to generate new ideas about the brain and the processing of images. Rather than focus on the lack of vision these artists have, the exhibit spotlighted the uniqueness of their available vision. Nelson writes that those who are blind rely on spatial memory, imagination, and dreams rather than vision. ${ }^{74}$ He views visual impairments as a benefit to creating art, rather than a hindrance. The artists in Art of the Eye feel the way they see the world is more artistic and offers greater creativity than those that see with no impairment.

Many well known artists were diagnosed with cataracts, such as Monet, Cassatt, and Daumier, which research has shown affected the work that they produced. Even those without impairments are inspired by a world with little visibility. The lights and colors that some see when their eyes are closed is inspiring not only to the visually impaired, but to the sighted as well. Perception of the sighted is investigated throughout art, but rarely of the visually impaired. The visually impaired depend on their own mechanisms to make assumptions about depth. When observing Op Art we are relying on our own individual perceptions that lead us t o make assumptions about how we construct our reality.

Art of the Eye is inspiring in its acknowledgement of individual perception. Each human being perceives in a unique way, whether sighted or visually impaired. The stories about and research on the visually impaired are included to show the importance of experience and knowledge of the world in establishing vision, both literally and figuratively. This can also be reversed to say that experiencing and studying the illusory effects of Op Art offers a deeper understanding of the world around us. In the same way

\footnotetext{
${ }^{74}$ Ibid., 11 .
} 
we need knowledge to perceive images we use the abstract images of Op Art to perceive the world. The individual perceptions of artists have contributed to art's progress over the centuries and the Op artists continued this expansion of art's role by making the idea of individual perception the basis for forming the world; each individual when viewing Op Art realizes that they must personally translate their perception. 


\section{CONCLUSION}

Our neurobiology shapes our perceptions and is exploited by Op Art which causes viewers to examine how individual perception reveals their world and influences their concepts of reality. By creating tension and disrupting the everyday balance of life, their work forces an examination of underlying assumptions opening the world to multiple possibilities. The following quotes by Riley and Vasarely respectively illustrate the goals of the Op artists as well as the ideas represented throughout this thesis and exhibition. Riley said,

I have always believed that perception is the medium through which states of being are directly experienced. There should, that is to say, be something akin to a sense of recognition in the work, so that the spectator experiences at one and the same time something known and something unknown. I have never made any use of scientific theory or scientific data, although I am well aware that the contemporary psyche can manifest startling parallels on the frontier between the arts and the sciences. ${ }^{75}$

Victor Vasarely explored the world of physics and became fascinated with its questions. Matter, according to wave mechanics is both wave and particle; this duality inspired Vasarely. He said,

Carried by the waves, I let myself be swept forward, now toward the atom, now toward the galaxies, passing through attractive or repelling fields. Could the Universe be but one grandiose equation? ${ }^{76}$

\footnotetext{
${ }^{75}$ Bridget Riley, "Perception is the Medium," Art News 64 (Oct. 1965): 32-33, 66.

${ }^{76}$ Marcel Joray, Vasarely: Plastic Arts of the Twentieth Century (Neuchatel, Switzerland: Editions du Griffon, 1969), 74.
} 
Vasarely's 'plastic unity' is a principle in which shapes and color interact according to a set formula based on geometry and science; both form and color are one.

Sharp black white contrasts, the unendurable vibration of complementary colors, the flickering of rhythmed networks and permuted structures, the optical kineticism of plastic components, all physical phenomena present in our works, the role of which is no longer to create wonder or to plunge us into a sweet melancholy, but to stimulate us and to provide us with wild joys ${ }^{77}$

Op Art, as the evolution in painting of the abstraction of forms and experimentation with color to produce illusory perceptual effects, provides the viewer with a strong, visceral impact. It is this powerful sensation that distinguishes Op Art. The viewer's instant realization of a physical reaction that the illusory art provides is a shocking, even consciousness raising experience. The power and significance of Op Art is in the illusions and the sensations they cause. The sensations of dizziness, after-effects, motion, and even nausea impact the viewer with an involuntary response. It is this reaction of the individual body that sparks within the observer questions into why and how these responses occur. These questions then lead to the inquiry of how we perceive the world around us. By observing Op Art, the individual is left with the realization that reality is not always as our expectations seem but in fact is made up of multiple viewpoints which become more apparent when confronted by the perceptual facts presented by Op Art; and in fact that there is much more than first meets the eye.

\footnotetext{
${ }^{77}$ Ibid., 163.
} 


\section{REFERENCES}

Albers, Joseph. Interaction of Color: Revised and Expanded Edition. New Haven and London: Yale University Press, 2006.

American Association of Museums. The Accessible Museum, Model Programs of Accessibility for Disabled and Older People. DC: National Endowment for the Arts, 1992.

Arnheim, Rudolf. Visual Thinking. Berkeley and Los Angeles: University of California Press, 1969.

Arnheim, Rudolf. Art and Visual Perception: A Psychology of the Creative Eye. Berkeley and Los Angeles: University of California Press, 1954.

Ashton, Dore. "Moderns on the Move." Studio International 167, no. 854 (June 1964): 256- 259.

Barrett, Cyril. Op Art. New York: A Studio Book The Viking Press, 1970.

Bertholf, Robert J., Rudolf Arnheim and Henry Rand. Julian Stanczak: Decades of Light. New York: The Poetry/Rare Books Collection, University Libraries, The University at Buffalo, 1990.

Borgzinner, John. "Op Art: Pictures that Attack the Eye." Time 84, no. 17 (October 23 1964): 1-4. Time Archive. Database on-line; accessed September, 2008.

Brooks, Arthur, Kevin F. McCarthy, Elizabeth H. Ondaatje and Laura Zakaras. Gifts of the Muse: Reframing the Debate About the Benefit of the Arts. Santa Monica, CA: The Rand Corporation and Wallace Foundation, 2004.

California Arts Commission. Dimension: An Exhibition of Sculpture for the Sighted and Blind. CA, 1970.

Carlyle, Cora. "Design Phenomenon of Op Art." American Fabrics 68 (Summer 1965): 10.

Diehl, Gaston. Vasarely. New York: Crown, 1991. 
Follin, Frances. Embodied Visions: Bridget Riley, Op Art and the 1960's. High Holborn, London: Thames and Hudson, 2004.

Gardner, Laura and Gerda Groff. What Museum Guides Need to Know: Access for Blind and Visually Impaired Visitors. New York, NY: American Foundation for the Blind, 1990.

Gregory, R.L., Colin Blakemore and E. H. Gombrich. Illusion in Nature and Art. Macmillan Publishing Company, 1980.

Greenberg, Clement. Art and Culture Critical Essays. Boston: Beacon Press, 1961.

Goldin, Amy. “A Note On Opticality.” Arts Magazine (May 1966): 53-54.

Harris, Jonathan. Writing Back to Modern Art after Greenberg, Fried, and Clark. London and New York: Routledge Taylor and Francis Group, 2005.

Hess, Thomas B. "You Can Hang it in the Hall." Art News 64 (April 1965): 41-43, 49-50.

Houston, Joe. Optic Nerve: Perceptual Art of the 1960's. London, New York: Merrell Publishers Limited, 2007.

Joray, Marcel. Vasarely: Plastic Arts of the 20th Century. Neuchatel, Switzerland: Editions du Griffon, 1969.

Joray, Marcel. Vasarely II: Plastic Arts of the 20th Century. Neuchatel, Switzerland: Editions du Griffon, 1970.

Julesz, Bela. "Texture and Visual Perception.” Scientific American (Feb. 1965): 38-48.

Kenny, Alice P. Access to the Past: Museum Programs and Handicapped Visitors. Nashville, TN: American Association for State and Local History, 1937.

Kohler, Wolfgang. The Task of Gestalt Psychology. Princeton, New Jersey: Princeton University Press, 1969.

Kurson, Robert. Crashing Through: A True Story of Risk, Adventure, and the Man Who Dared to See. New York, NY: Random House, 2007.

Lanes, Jerrold. "Current and Forthcoming Exhibitions: New York." The Burlington Magazine 107 (April 1965): 217-220.

Liscenco, Yasha. Art Not By Eye: The Previously Sighted Visually Impaired Adult in Fine Arts Programs. New York, NY: American Foundation for the Blind, 1972. 
Livingston, Margaret. Vision and Art: The Biology of Seeing. New York, NY: Harry N. Abrams, Incorporated, 2002.

Lunde, Karl. Richard Anuszkiewicz. New York: Harry N. Abrams Incorporated, 1977.

Lunde, Karl. "Richard Anuszkiewicz." Arts Magazine 49, no. 7 (March 1975): 56-57.

Mcllhany, Sterling. "A Close Look at Optical Art: Paintings, Constructions, and Designs Created to Confound and Amaze the Eye." American Artist 34 (June 1970): 3237.

M-L. D’Otrange, Mastai. “The Foundations of Op Art.” Connoisseur 159 (July 1965): 215.

Nelson, Scott. Art of the Eye: An Exhibition On Vision. St. Paul, MN: Delta Gamma Foundation and FORECAST, 1986.

Oster, Gerald. "Optical Art.” Applied Optics 4, no. 11 (Nov. 1965):1359-69.

Riley, Bridget. "Perception is the Medium." Art News 64 (October 1965): 32-3, 66.

Rimanelli, David. "Beautiful Loser: Op Art Revisited." Artforum 45, no. 9 (May 2007): 315-26.

Robbins, Daniel and Eugenia. "Josef Albers: Art is Looking at Us" Studio International 164, no. 850 (Feb. 1964): 54-57.

Seitz, William C. The Responsive Eye. New York, NY: Case-Hoyt Group The Museum of Modern Art, 1965.

Shimojo, Shinsuke. "Afterimage of Perceptually Filled-in Surface." Science 293, no. 31 (Aug. 2001): 1677-80.

Shinn, Matt. "Seeing the Light." Museums Journal 105, no. 1 (Jan. 2005): 24-27.

Spies, Werner. Victor Vasarely. New York: N.N. Abrams, 1971.

Trevor-Roper, Patrick. The World Through Blunted Sight: An Inquiry into the Influence of Defective Vision on Art and Character. London: Thames and Hudson, 1970.

Weinhart, Martina, Mark Hollein, and Frances Follin. Op Art. Frankfurt: Schirn Kunsthalle, 2007.

Wenger, Robert. "Visual Art, Archaeology, and Gestalt." Leonardo 30, no. 1 (1997): 3546. JSTOR. Database on-line; accessed June 25, 2008. 
Wissman, Fronia. Albers. New Haven, Connecticut: University Art Gallery, 1978.

Zanker, J. "Looking at Op Art from a Computational Viewpoint." Spatial Vision 17, no. 1-2 (2004): 75-92. 


\section{APPENDICES}

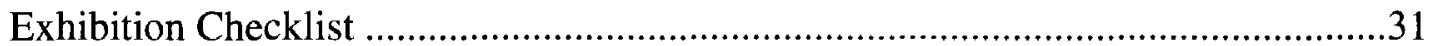

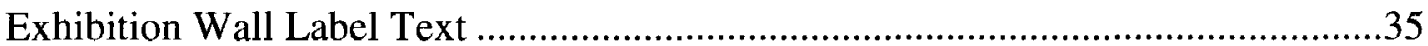




\section{EXHIBITION CHECKLIST}

Yaacov Agam

Title: Untitled (kinetic \# 7/20)

Medium: plastic

Date: ND

Joseph Albers

Title: Interaction of Color

Medium: Folio

Date: 1963

Richard Anuszkiewicz

Title: Illustration for "Inward eye"

Medium: Print (Serigraph color)

Date: N.D.

Title: Inward eye

Medium: Print (Serigraph color)

Date: N.D.

Ben Cunningham 
Title: Painting for a corner (2 Panels)

Medium: Painting (oil on masonite)

Date: 1950

Sally Drummond

Title: Night Flight

Medium: Painting

Date: 1978

Bridget Riley

Title: Fall

Medium: poster reproduction

Julian Stanczak

Title: Filtration

Medium: Print (Silkscreen, color)

Date: 1979

Victor Vasarely

Title: Untitled (blues, gold, violet on brown)

Medium: Print (Serigraph 59/425, color)

Date: N.D.

Title: Untitled (geometric composition) 
Medium: Print (Serigraph color)

Date: N.D.

Vasarely: Plastic Arts of the 20th Century

Introduction: Marcel Joray

Text: Victor Vasarely

Editions du Griffon

Neuchatel, Switzerland, 1969

Vasarely II: Plastic Arts of the 20th Century

Introduction: Marcel Joray

Text: Victor Vasarely

Editions du Griffon

Neuchatel, Switzerland, 1970

John Whitesell

Title: "Homage to Malevich"

Medium: Screen Print

Date: 1971

Title: "Red Print"

Medium: Screen Print on paper and acrylic sheet 
Date: 1971

Title: "Lorelei"

Medium: Screen Print

Date: 1973

Title: "Resonance I"

Medium: Acrylic painting

Date: 1965 


\section{EXHIBITION WALL TEXT}

Intro Text:

Op Art: Perceptions of Reality examines the connections between art and science. Illusions, formed in the mind, can be observed in Op Art. These effects vary from person to person thus privileging an individual perception. This individuality of experience inspired the Op artists. These artists used science as a basis in their work. Neurobiology and Gestalt psychology were the sciences that influenced many Op artists particularly their ideas about perception and the explanation of the illusory phenomena of Op Art. Op Art connected art and science as both fields were influenced by the other. Scientists learned from Op Art about visual processes that operate in our mind and eye (and artists gained understanding of why these phenomena worked).

The goal of the exhibition is not to force an experience, but to present the idea that Op Art provides perceptual experiences which cause viewers to question the world we live in and show how individual perception provides an opportunity for acknowledgement of a universe of multiple dimensions and realities. 
Anuszkiewicz/ Stanczak Text:

Many artists during the 1960's and 1970's drew inspiration from the journal Scientific American. Op Art by Richard Anuszkiewicz and Julian Stanczak which often provokes jarring and jittery effects, offered a physical excitement which the field of optics and Gestalt phenomena help explain. Their work demonstrates an effect caused by the juxtaposition of two colors of equiluminance. Equiluminosity is when two colors, simultaneously lighter and darker than the other, are placed side by side. Our brain uses luminance to decide positions. If two colors are of equal luminance they will look jittery to the eye since no position is decipherable. Anuszkiewicz explores the energy of color with the idea that electricity is the effect of the interaction of physical objects, thus presenting energy and space to the viewer. Stanczak's use of multiple colors and a grid structure point to his fascination with space and the multiple views one can have of reality.

Whitesell/ Agam Text:

Moiré, which is seen in the work of John Whitesell, is a phenomenon found in Op that occurs when two patterns are placed on top of each other. The moiré is the new pattern that is formed when the lines of the two intersect. The new pattern creates an effect of motion which is determined by the spacing, or distance, of the two original patterns. It is the viewer who deciphers this motion as the eye moves across the surface. The moiré effect becomes more numerous depending on the degree of angle and curve of the 
pattern. Yaacov Agam's kinetic piece shifts and creates new patterns offering the viewer multiple views and points to his fascination with a continuous universe of multiple dimensions. He is inspired by the idea of a space-time continuum and the fourth dimension and offers shifting multiple viewpoints in his work as a visual representation of this idea. The individual is left with the concept that reality is not always as it seems and that it often depends on the eye of the viewer.

Riley/ Whitesell

Motion and afterimage flickering are explained by the center/surround organization of the ganglion cells (the frontal part of the neural tissue) and the slower response time of the surround neurons. Our center neurons respond best to rapid changes rather than gradual ones. The curvature and pattern of lines in work such as Bridget Riley's Fall poster are another way to create an illusion of motion. The depth observed can be explained by the repetition of patterns and the varying degree of spacing between lines and curves. The retina, responsible for matching images, cannot decipher between these repetitive patterns in a two-dimensional scene. The repetition of pattern causes the retina to confuse the matching of images since any part of the scene could be correct. Many of the black and white Op Art works use this effect as can be seen in the work of Riley and Whitesell.

The great popularity of Op Art as a cultural event sparked a debate between art and science; the following are quotes from Bridget Riley in response to the debate:

I have always believed that perception is the medium through which states of being are directly experienced. There should, that is to say, be something akin to a 
sense of recognition in the work, so that the spectator experiences at one and the same time something known and something unknown. I have never made any use of scientific theory or scientific data, although I am well aware that the contemporary psyche can manifest startling parallels on the frontier between the arts and the sciences.

Vasarely/ Cunningham/ Drummond:

Victor Vasarely explored the world of physics and became fascinated with its questions.

Matter according to Wave Mechanics is both wave and particle; this duality inspired Vasarely.

Carried by the waves, I let myself be swept forward, now toward the atom, now toward the galaxies, passing through attractive or repelling fields. Could the Universe be but one grandiose equation?

"The plastic unity" is a principle in which shapes and color interact according to a set formula based on geometry and science, both form and color are one. Victor Vasarely said,

Sharp black- white contrasts, the unendurable vibration of complementary colors, the flickering of rhythmed networks and permuted structures, the optical kineticism of plastic components, all physical phenomena present in our works, the role of which is no longer to create wonder or to plunge us into a sweet melancholy, but to stimulate us and to provide us with wild joys

\section{Albers Text:}

Joseph Albers, a Bauhaus artist who became an influential teacher in America, created work that responded to the context in which it was represented, (and produced a text, "The Interaction of Color" that became an important teaching tool in studio art programs) thus demonstrating visually the many possibilities of perception. Colors can be manipulated by their juxtaposition and background. "When you really understand that 
each color is changed by a changed environment, you eventually find that you have learned about life as well as about color"

Conclusion Text:

Op Art provides demonstrable evidence that reality, including the scientific method, is subjective. The sciences of human perception and their experiments relative to principles that they have established for understanding human perception and observation confirm the nature of the individual viewpoint (the subjective) as being the only method to interpret the world. Our scientific laws are formulated through observations made by our individual senses, which differ from person to person. When viewing illusory effects such as motion, moiré patterns, afterimages or jarring complementary colors the body and mind are experiencing a reality which lends itself to the unknown. Op Art shows that there is not only one reality, but multiple realities all as real and correct as the next, and this confounding conundrum provides Op Art with its intrigue and lasting appeal. 


\section{CURRICULUM VITAE}

NAME: Christine Michelle Humphrey

ADDRESS: 110 Emily St.

Beckley WV, 25801

DOB: Beckley, WV- August 25, 1982

Education: B.A., Sociology (concentration in Anthropology)

Marshall University

Huntington, WV

2000-05

AWARDS: Allen R. Hite Assistantship

2007-08

A. Michael Perry Scholarship

2000 


\section{ADDENDUM}

Exhibition Announcement Card

Exhibition Catalogue Brochure

Images from Installed Exhibition on CD 